\title{
Plastic bags as simple photobioreactors for cyanobacterial hydrogen production outdoors in Moscow region
}

\author{
Evgeny Shastik $^{1} \cdot$ Anastasiya Romanova $^{1} \cdot$ Tatyana Laurinavichene $^{1} \cdot$ Ekaterina Petushkova $^{1} \cdot$ Hidehiro Sakurai $^{2}$. \\ Anatoly Tsygankov ${ }^{1}$
}

Received: 10 August 2019 / Accepted: 9 November 2019 / Published online: 16 November 2019

(c) The Author(s) 2019

\begin{abstract}
The application of transparent plastic bags with a gas barrier layer as inexpensive photobioreactors for $\mathrm{H}_{2}$ production by the cyanobacterium Anabaena sp. PCC $7120 \Delta$ Hup mutant cells was explored outdoors in Moscow region for the first time. Two experiments were performed in July and August, the average daily temperature being 21.7 and $20.6{ }^{\circ} \mathrm{C}$, the average daily light intensity being 290 and $340 \mu \mathrm{mol}$ photon $\mathrm{m}^{-2} \mathrm{~s}^{-1}$ in experiment \#1 and \#2, respectively. The maximal $\mathrm{H}_{2}$ production rate was $20.6 \mathrm{~mL}_{\text {day }}{ }^{-1} \mathrm{~L}^{-1}$ of culture, with accumulation of $33.2 \mathrm{~mL} \mathrm{~L}^{-1}$ during 5 days and a final $\mathrm{H}_{2}$ content of $1.1 \%$ (v/v). Molecular nitrogen added to the Ar gas at 3.3\% significantly affected neither the rate nor the duration of $\mathrm{H}_{2}$ production. Low morning temperatures as well as high daytime light intensities (especially at low cell concentrations) seemed to reduce the $\mathrm{H}_{2}$ production rate. The activities obtained were lower as compared to the previously reported data. It could be attributable to suboptimal weather conditions and simple device arrangement. However, results prove that $\mathrm{H}_{2}$ production by cyanobacteria is still feasible outdoors in plastic bags, the cheapest photobioreactors.
\end{abstract}

Keywords Anabaena sp. PCC $7120 \Delta$ Hup mutant $\cdot$ Hydrogen production $\cdot$ Outdoor cultivation $\cdot \mathrm{H}_{2}$ barrier plastic photobioreactor

\section{Introduction}

Photobiological production of hydrogen $\left(\mathrm{H}_{2}\right)$ is considered to be one of the most promising technologies for replacing or complementing fossil fuel-derived energy. In contrast with electricity generated by solar panels and wind mills, $\mathrm{H}_{2}$ is more easily stored and transported from overseas [1-5].

Among phototrophic microorganisms, purple bacteria are characterized by the highest rates of $\mathrm{H}_{2}$ production. However, the presence of organic substances and anaerobic conditions are required for this process. Unlike that, autotrophic microorganisms such as nitrogen-fixing filamentous heterocyst-forming cyanobacteria do not require organic substances, have simple nutritional needs, use $\mathrm{N}_{2}$ from the

Anatoly Tsygankov

ttt-00@mail.ru

1 Institute of Basic Biological Problems, Russian Academy of Sciences, Pushchino, Moscow Region 142290, Russia

2 Research Institute for Photobiological Hydrogen Production, Kanagawa University, Hiratsuka, Kanagawa 259-1293, Japan air as the nitrogen source for growth and produce $\mathrm{H}_{2}$ using specialized cells called heterocysts.

Laboratory cultivation of cyanobacteria for biomass harvesting usually presents no difficulties, requiring only inorganic culture medium, air blowing with $\mathrm{CO}_{2}$ supplementation, gentle mixing and compliance with temperature and light regimes. A description of suitable photobioreactors $(\mathrm{PhBR})$ for this purpose is presented in several reviews [6-8].

For large-scale production of cyanobacterial biomass, the simplest and cheapest solution is cultivation in open ponds or pools, but for harvesting $\mathrm{H}_{2}$, we need closed bioreactors [9]. The laboratory conditions for $\mathrm{H}_{2}$ production by cyanobacterial suspensions have been studied in detail. The main influencing factors are light intensity, temperature and the nitrogen source [10]. The highest rates of $\mathrm{H}_{2}$ production [100-130 $\mu \mathrm{mol} \mathrm{h}^{-1} \mathrm{mg}$ chlorophyll $\left.(\mathrm{Chl})^{-1}\right]$ in short-term experiments were achieved using genetically modified strains (in particular, with elimination of the $\mathrm{H}_{2}$ uptake hydrogenase activity $\Delta$ Hup) $[11,12]$.

For laboratory-scale $\mathrm{H}_{2}$ production by cyanobacteria, one can use different types of PhBRs: cylindrical, panel, tubular, 
spiral with mechanical or airlift mixing [10, 13]. Experiments with Anabaena variabilis PCC 7120 and mutant AMC 414 (lacking the $\mathrm{H}_{2}$ uptake activity) were performed in a laboratory tubular PhBR with control of $\mathrm{pH}$, temperature and optical density under chemostat and modes [14]. The production of $\mathrm{H}_{2}$ by $\Delta$ Hup mutants took place under air, unlike the wild types where in the presence of oxygen, $\mathrm{H}_{2}$ was used as the electron donor and its yield greatly decreased. In the Ar atmosphere, $\mathrm{H}_{2}$ evolution increased in both strains, but in the mutant it was maximal, reaching $13.8 \mathrm{~mL} \mathrm{~L}^{-1} \mathrm{~h}^{-1}$. Under simulated outdoor conditions in an automated helical tubular $\mathrm{PhBR}$, A. variabilis $\mathrm{PK} 84$ did produce $230 \mathrm{~mL} \mathrm{H}_{2}$ per $\mathrm{PhBR}$ (4.35 L) during 12-h light period under aeration [15].

Few attempts to obtain $\mathrm{H}_{2}$ outdoors using reactors with cyanobacteria have been made. The above-mentioned study of the A. variabilis PCC 7120 mutant (AMC 414) was also continued outdoors. In this case, the rate of $\mathrm{H}_{2}$ evolution in the chemostat mode was about $3 \mathrm{~mL} \mathrm{~L}^{-1} \mathrm{~h}^{-1}$ [14]. As another example, $\mathrm{H}_{2}$ production by $A$. variabilis $\mathrm{PK} 84$ in a spiral tubular PhBR during purging air supplemented with $\mathrm{CO}_{2}$ was observed in a batch or chemostat mode with $\mathrm{pH}$ control [16]. Under the experimental conditions (on the roof of a building in London), the average rate of $\mathrm{H}_{2}$ evolution was $8 \mathrm{~mL} \mathrm{~L}^{-1} \mathrm{~h}^{-1}$. Recently, Synechocystis sp. strain PCC 6803 was cultivated outdoors in 50-L tubular PhBR, with maximum $\mathrm{H}_{2}$ production rate of $0.05 \mathrm{~mL} \mathrm{~L}^{-1} \mathrm{~h}^{-1}$ under dark anaerobic conditions [17].

Although extensive researches have been carried out on photobiological $\mathrm{H}_{2}$ production by various photosynthetic organisms using various types of PhBRs, none of the systems are actually operating in a commercially viable state. For low-cost photobiological $\mathrm{H}_{2}$ production, one of the great issues is the need for inexpensive PhBRs. Amos [18] made a lifecycle assessment of $\mathrm{H}_{2}$ production by the green alga Chlamydomonas, and pointed out that the cost of PhBRs should not exceed US $\$ 10 \mathrm{~m}^{-2}$ for economically viable $\mathrm{H}_{2}$ production.

For inexpensive PhBRs, Sakurai et al. [1, 9, 19] proposed the use of large transparent plastic bags with low permeability to $\mathrm{H}_{2}$ floating on the sea surface on calm belts. The potential usefulness of such PhBRs was tested under laboratory conditions using the $\Delta$ Hup mutant of the cyanobacterium Nostoc sp. PCC 7422 [20]. However, the above experiments were carried on a small scale (the culture volume of $50 \mathrm{~mL}$ ) under the light from fluorescent lamps in a laboratory.

To summarize, even if laboratory experiments suggest that cyanobacteria are promising for producing hydrogen, there are only a few outdoor studies. And no attempt has been made to make this process more cost effective.

The goal of our work was to explore the possibility of $\mathrm{H}_{2}$ production by Anabaena sp. PCC $7120 \Delta$ Hup for the first time outdoors in Moscow region using cheap PhBRs-transparent plastic bags with a gas barrier layer (Be-P).

\section{Materials and methods}

\section{The object of study and cultivation conditions}

The strain used was a mutant strain of cyanobacteria Anabaena sp. PCC 7120 ( $\Delta$ Hup), created by disrupting the uptake hydrogenase gene hupL [21], and provided by Prof. Inoue, K., Kanagawa University, Japan.

The inoculum was grown photo-autotrophically in 300mL Erlenmeyer flasks in Allen-Arnon medium [22] diluted 8 times (AA/8) supplemented with $5 \mathrm{mM}$ TES-KOH buffer ( $\mathrm{pH}$ 8.2), without adding bound nitrogen but with the addition of streptomycin and spectinomycin, $2 \mu \mathrm{g} \mathrm{mL}^{-1}$ each [21]. The cultivation was carried out at $27{ }^{\circ} \mathrm{C}$ in light (30 $\mu$ mol photon $\mathrm{m}^{-2} \mathrm{~s}^{-1}$ ) under air with shaking at $95 \mathrm{rpm}$.

For experiments, culture $(\sim 14 \mathrm{~L})$ was grown under the conditions indicated above (except shaking). A set of bottles $(1.7 \mathrm{~L})$ were sparged with air $+1 \% \mathrm{CO}_{2}$ through sterile membrane filters with a pore size of $0.2 \mu \mathrm{m}$ (Pall, Ann Arbor, MI, USA).

\section{The design of PhBRs}

To study $\mathrm{H}_{2}$ production, cyanobacteria were placed in PhBRs $-36 \mathrm{~cm} \times 50 \mathrm{~cm}$ flexible plastic Be-P bags [20], which have a polyacrylate gas barrier layer. In the first experiment, each PhBR was a flat bag with two ports: for culture and gas sampling [20]. In the second experiment, a rigid internal stainless steel frame was placed inside the bag, increasing the height of the bag to ensure the gas flow from one PhBR to another. This design was equipped with one port for culture sampling and two ports for gas inlet and outlet. Before the start of the experiment, the bags were autoclaved.

\section{The experimental device}

The experimental device (Fig. 1) consisted of a water bath to smooth out temperature fluctuations; stabilizing belts to fix the bags, temperature and light sensors connected to the QMbox modular measuring system (RG Tekhnoloji, Russia), and computer to record data. Temperature sensors were submerged in the water bath.

\section{Cultivation conditions}

In the Experiment \#1, the grown cells were centrifuged (900g, $2 \mathrm{~min}$ ) and suspended in AA/8-N medium at Chl concentration of $23.3 \mathrm{mg} \mathrm{L}^{-1}$. The volume of the culture in each $\mathrm{PhBR}$ was $1 \mathrm{~L}$. The gas phase $(3 \mathrm{~L})$ was replaced with Ar supplemented with $5 \% \mathrm{CO}_{2}$, and $3.3 \%$ of $\mathrm{N}_{2}$ was 


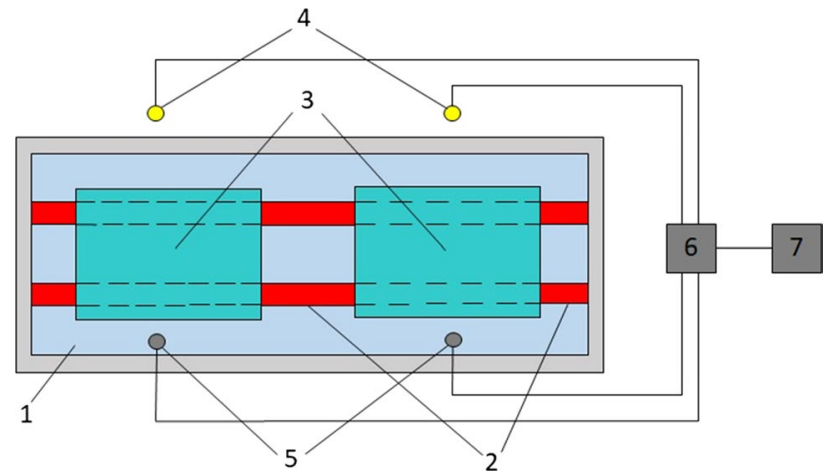

Fig. 1 Schematic diagram of cultivation. 1-water bath; 2-stabilization belts; 3-bags with culture; 4-light sensors; 5-temperature sensors; 6-device for monitoring temperature and solar radiation; 7-computer

added to the PhBR 1. The cultivation was carried out in Central Russia (Moscow region, $54^{\circ} 50^{\prime} \mathrm{N}$ and $37^{\circ} 37^{\prime} \mathrm{E}$ ) from July 20-25, 2016 under natural light and temperature (on the roof of a four-story building).

In the Experiment \#2, the culture was not concentrated, but previously adapted to high-light intensities by gradual increase from 30 to $700 \mu \mathrm{mol}$ photon $\mathrm{m}^{-2} \mathrm{~s}^{-1}$ within 4 days. The outdoor experiments began under reduced light intensity using light filters. The light filter consisted of several layers of netting, which reduced light intensity 2-7 times (the coefficient was determined in laboratory tests). Later, the number of layers varied, providing different light intensities in PhBR 3 and PhBR 4. The volume of culture in the PhBR was $1 \mathrm{~L}$ with initial Chl content $\sim 4.3 \mathrm{mg} \mathrm{L}^{-1}$, the volume of the gas phase being $3 \mathrm{~L}$. Air supplemented with $0.5-1.0 \% \mathrm{CO}_{2}$ was successively sparged through PhBR 3 and 4 at $20-100 \mathrm{~mL} \mathrm{~min}^{-1}$. The cultivation was performed outdoors in the same place, August 18-23, 2016 (Fig. 2).

\section{Gas analysis}

In the Experiment \#1, gas phase was analyzed twice a day: at 8:00 and 20:00. $\mathrm{H}_{2}$ yield and production rate were calculated based on its concentration and the volume of the gas phase of PhBR. Calculations referred to the morning (5:00-8:00), daytime (8:00-20:00), daylight (the whole light period 5:00-20:00) or the whole day (20:00-20:00). Since no $\mathrm{H}_{2}$ measurements were taken at 5:00, we assumed that at night, there was neither $\mathrm{H}_{2}$ production nor consumption, therefore, the $\mathrm{H}_{2}$ concentration obtained at 20:00 the previous day was assumed to be equal to the $\mathrm{H}_{2}$ concentration at 5:00 the next day.

In the Experiment \#2, the rate of $\mathrm{H}_{2}$ evolution was calculated based on its concentration and the air flow rate, so the $\mathrm{H}_{2}$ accumulation was further calculated. In this case, we assumed that $\mathrm{H}_{2}$ concentration at night was zero due to the fast removal of previously formed $\mathrm{H}_{2}$ with air flow. The current rates of $\mathrm{H}_{2}$ evolution or averaged rates were calculated during morning, daytime, daylight or the whole day (as indicated in the captions to the figures and tables).

The concentration of $\mathrm{H}_{2}$ in the gas phase was measured at $22{ }^{\circ} \mathrm{C}$ by gas chromatography (LHM80, Moscow, Russia), equipped with a thermoconductivity detector and a $1 \mathrm{~m} \times 3 \mathrm{~mm}$ with molecular sieve column (running temperature, $40{ }^{\circ} \mathrm{C}$ ). Argon was used as the gas carrier [23]. Gas samples $(0.5 \mathrm{~mL})$ were withdrawn from PhBR using locked syringes and transferred to chromatograph. Hydrogen concentration was calculated on the basis of calibration using ECOCHROM program.

\section{Analytical methods}

Chl $a$ concentration was measured spectrophotometrically at $664 \mathrm{~nm}$ (U-VIS 1240 Mini, Shimadzu, Japan) after extraction with $85 \%$ methanol. The light intensity (photosynthetically active radiation, $400-700 \mathrm{~nm}$ ) was determined with a quantum meter (Quantum Meter, model: QMSW-SS, USA).
Fig. 2 Experiment \#2: two out of three initial PhBRs were in operation (a), single bag with culture (b)
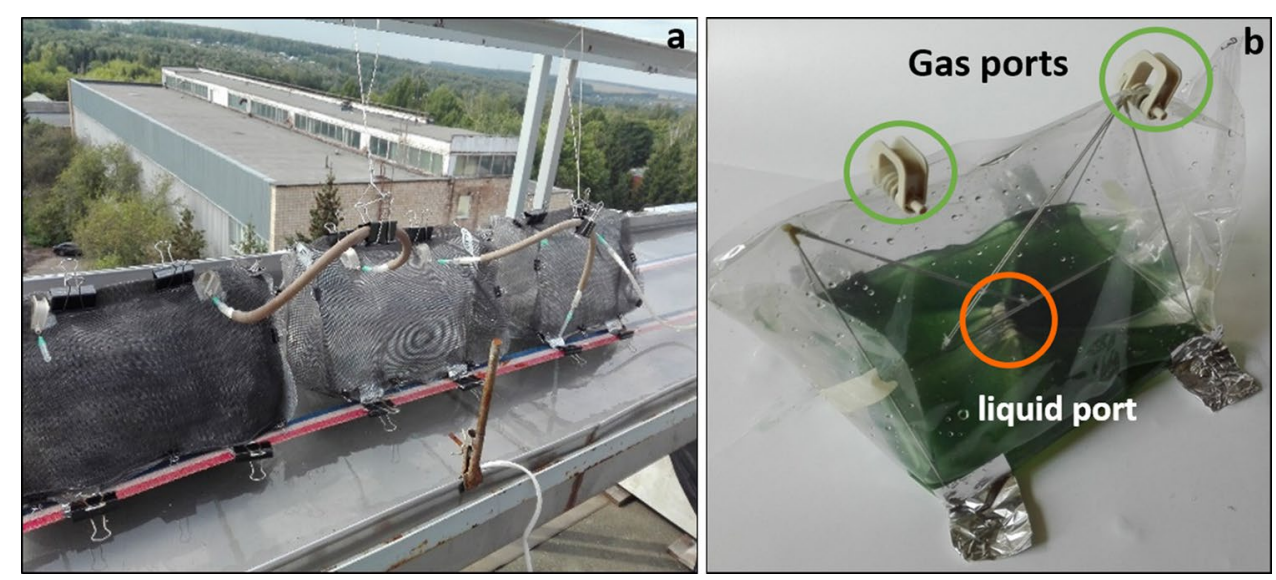
To check pH value, $5 \mathrm{~mL}$ of culture was taken through the culture port using a sterile syringe. If necessary, $\mathrm{pH}$ was adjusted to 8.2 with $0.5 \mathrm{M} \mathrm{NaHCO}_{3}$. In both experiments, the culture was mixed manually by gently shaking the bag twice a day during sampling. The axenity of cyanobacteria culture was checked by light microscopy (LOMO MIKMED-2, Russia).

\section{Statistical data processing}

Statistical data processing was performed in the SigmaPlot 11.0 program. The average values of the results $\pm 95 \%$ confidence interval are presented.

\section{Results and discussion}

\section{Outlines of weather conditions during the two experiments}

Continuous monitoring of light intensity and temperature during the two experiments allowed us to characterize weather conditions. During Experiment \#1 (Fig. 3a), the average daily temperature was $21.7 \pm 0.4$, maximal 31.4 , and minimal $16.1{ }^{\circ} \mathrm{C}$. The average daily illumination was $290 \pm 40$, maximal 1520 , and minimal $<10 \mu \mathrm{mol}$ photon $\mathrm{m}^{-2} \mathrm{~s}^{-1}$. During Experiment \#2 (Fig. 3b), the average daily temperature was $20.6 \pm 0.4$, maximal 30.5 , and minimal $14.9^{\circ} \mathrm{C}$. The average daily illumination was $340 \pm 42$, maximal 1650 , and minimal $<10 \mu$ mol photon $\mathrm{m}^{-2} \mathrm{~s}^{-1}$. Hence, in Experiment \#1, the illumination was lower, and in Experiment \#2, the temperature was lower.

\section{The hydrogen production in Experiment \#1}

As indicated above, both the PhBRs were initially filled with $\mathrm{Ar}+\mathrm{CO}_{2}$, but $3.3 \%$ of $\mathrm{N}_{2}$ was added to the gas phase of $\mathrm{PhBR}$ 1. The patterns of $\mathrm{H}_{2}$ accumulation were similar in both PhBRs (Fig. 4a). The maximum rates of $\mathrm{H}_{2}$ production were at midday, but they varied over the observation period (Fig. 4b). The decrease in the maximum rate at 40th and 64th $\mathrm{h}$ correlated with the low daytime temperature and illumination (Fig. 4a).

The average rate of $\mathrm{H}_{2}$ production in the daytime in PhBRs 1 and 2 increased with the average light intensity (Fig. 5a). Similar dependence was shown in other outdoor experiments [16]. In more detail, the influence of light intensity was studied in Experiment \#2.

A decrease in the average rate of $\mathrm{H}_{2}$ evolution in the morning was observed with a decrease in temperature in the morning hours (Fig. 5b) or during the preceding night (not shown). Earlier, a low daily temperature was supposed to be the main limiting factor in obtaining $\mathrm{H}_{2}$ outdoors
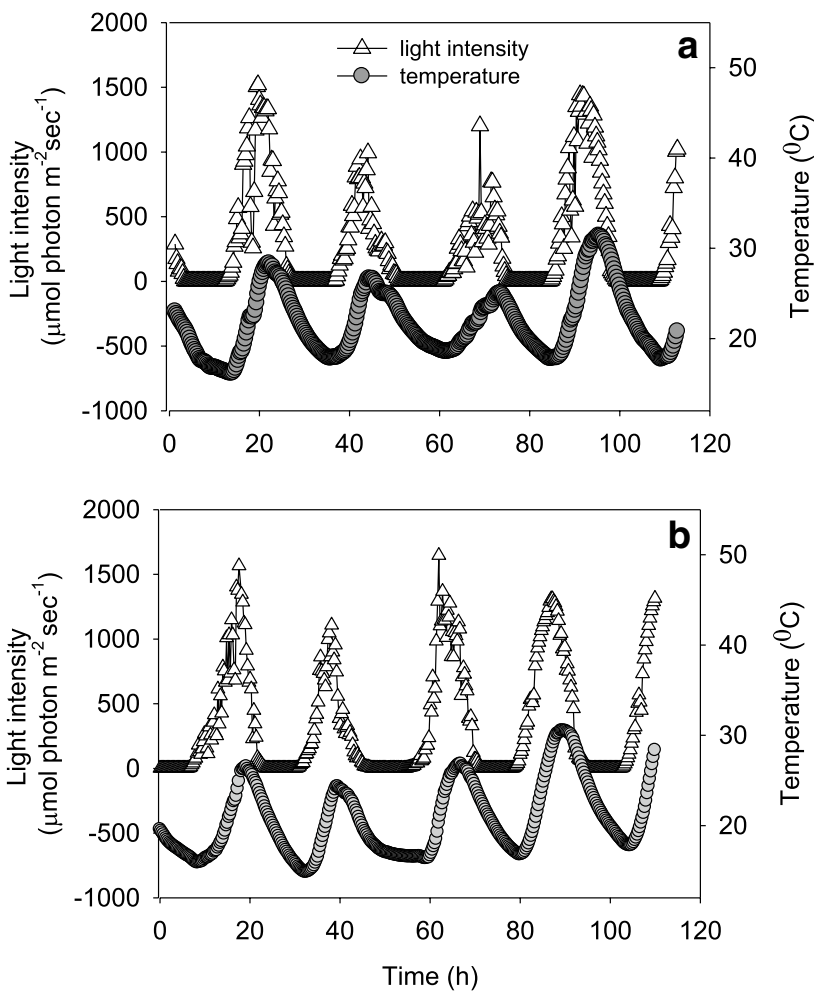

Fig. 3 The record of the light intensity and the temperature in Experiment \#1 (a, July 20-25, 2016) and in Experiment \#2 (b, August 18-23, 2016). The start of Experiment \#1 was at 14:00, the first measurement was at 20:00 (0 point). The start of Experiment \#2 was at 17:00 (0 point), the first measurement was at 13:00 the next day (point $20 \mathrm{~h}$ )

[16]. A decrease in $\mathrm{H}_{2}$ production activity with decreasing temperature is a matter of common knowledge [24, 25]. However, the effect should not be as dramatic as shown in Fig. 5b: about 10 times decrease was seen in $\mathrm{H}_{2}$ production rate with temperature decrease by only $3{ }^{\circ} \mathrm{C}$. We would like to attribute it to the mutual effect of low temperature and high-light intensity. Earlier in short-term laboratory experiments, we showed that at $16^{\circ} \mathrm{C}$, the photosynthetic activity of this strain was inhibited at light intensity above $300 \mu \mathrm{mol}$ photon $\mathrm{m}^{-2} \mathrm{~s}^{-1}$, while at higher temperatures no inhibition was observed even at $2800 \mu \mathrm{mol}$ photon $\mathrm{m}^{-2} \mathrm{~s}^{-1}$ [25]. Although the average light intensity in the morning was only about $100 \mu \mathrm{mol}$ photon $\mathrm{m}^{-2} \mathrm{~s}^{-1}$ and the average morning temperature was $15.1-16.6{ }^{\circ} \mathrm{C}$, the duration of the impact was much longer. Therefore, the photoinhibition may be one of the explanations for this dependence.

Torzillo and Vonshak [26] demonstrated that photoinhibition of photosynthetic activity was much higher at temperatures below and above the optimum, in the open ponds or closed systems, correspondingly. Outdoor experiments with Synechocystis PCC 6803 in $50 \mathrm{~L}$ tubular PhBR 


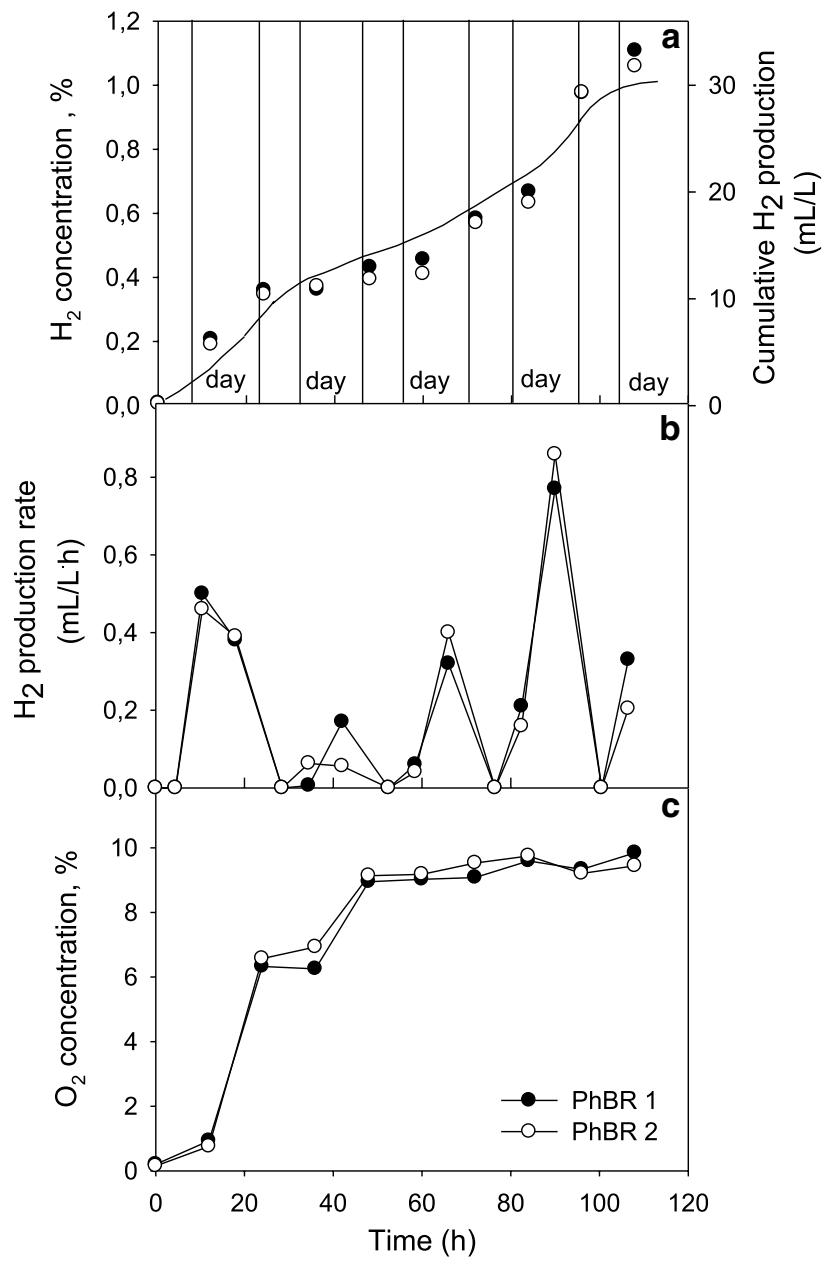

Fig. 4 Concentration and accumulation of $\mathrm{H}_{2}$ (a), the rate of $\mathrm{H}_{2}$ evolution (b) and the concentration of $\mathrm{O}_{2}(\mathbf{c})$ in Experiment \#1. The gas phase of PhBR 1 was initially supplied with $3.3 \%$ of $\mathrm{N}_{2}$

showed that photoinhibition strongly affected maximum quantum yield of PSII at low biomass concentration [17].

The presence of $\mathrm{N}_{2}$ in the Ar gas phase might be helpful for prolonged $\mathrm{H}_{2}$ production during 20 days as was shown earlier [27]. However, in our rather short experiments, it significantly affected neither the current $\mathrm{H}_{2}$ production rates, nor its accumulation (Fig. 4a, b).

It should be noted that the final $\mathrm{N}_{2}$ concentration in $\mathrm{PhBR}$ 2 (without $\mathrm{N}_{2}$ addition) did not exceed $0.3 \%$, which proves that these bags have negligible permeability to at least $\mathrm{N}_{2}$. We cannot judge the permeability to $\mathrm{H}_{2}$ based on our data, but the previous investigation shows that it was very low [20]. The final oxygen concentration was $\sim 10 \%$ (Fig. 4c), i.e., lower than that in the air and due evidently to the photosynthetic activity of cyanobacteria. The maximum increase in $\mathrm{O}_{2}$ concentration was observed in the first 2 days of the experiment, later the $\mathrm{O}_{2}$ concentration did not increase (Fig. 4c). This could be due to a decrease in photosynthetic activity, therefore $40 \mathrm{~mL}$ of $0.5 \mathrm{M} \mathrm{NaHCO}_{3}$ was added at
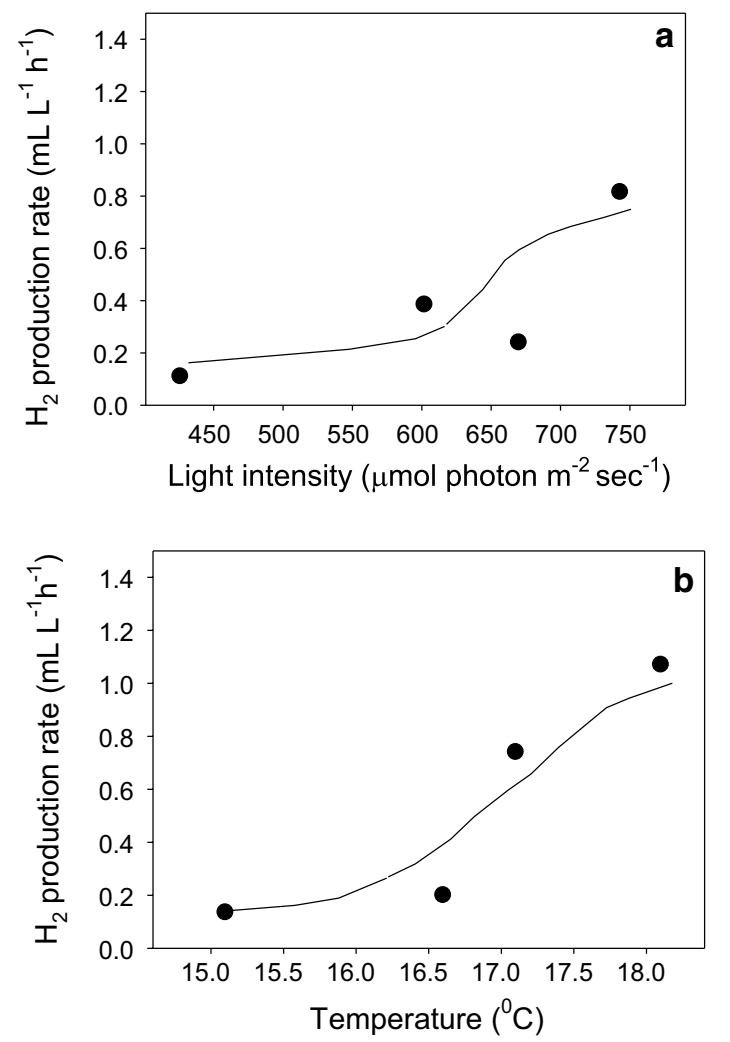

Fig. 5 Average $\mathrm{H}_{2}$ production rate in Experiment \#1 (PhBRs 1 and 2) depending on the average light intensity in the daytime (8:00-20:00) (a) and depending on the morning temperature (5:00-8:00) (b)

113th $\mathrm{h}$ (not shown). However, $\mathrm{O}_{2}$ evolution did not resume, and $\mathrm{H}_{2}$ evolution ceased. Perhaps this was due to inadequate mixing, because control $\mathrm{pH}$ measurement (7.2) turned out to be incorrect-actual $\mathrm{pH}$ was 10.2 , which was the reason for experiment termination. Mixing technique in $\mathrm{PhBR}$ of such type should be thought out. It is well-known that appropriate stirring strongly affected the biomass output of cyanobacteria [28]. However, for a large-scale cultivation in the future, mixing seems to be improbable to execute.

\section{The hydrogen production in Experiment \#2}

Since in Experiment \#1, both PhBRs showed similar results, the influence of light intensity (four different values) was studied in parallel in two PhBRs (two values for each PhBR). The light intensity was changed using filters as indicated in Materials and Methods.

Both the maximum and average (per daylight) $\mathrm{H}_{2}$ production rates were the lowest in the unshadowed culture at $1400 \mu \mathrm{mol}$ photon $\mathrm{m}^{-2} \mathrm{~s}^{-1}$ (Table 1), which suggested the possibility of photoinhibition. It is well-known that the effect of light intensity may be different in various strains of cyanobacteria [10]. For example, low-light intensity was recommended for laboratory $\mathrm{H}_{2}$ production by some 
Table 1 Effect of light intensity on the $\mathrm{H}_{2}$ production rate (during daylight) in Experiment \#2

\begin{tabular}{lll}
\hline $\begin{array}{l}\text { Light intensity at noon with shading, } \\
\mu \mathrm{mol} \text { photon } \mathrm{m}^{-2} \mathrm{~s}^{-1}\end{array}$ & $\begin{array}{l}\mathrm{H} \\
\mathrm{H}\end{array}$ production rate, $\mathrm{mL}$ \\
\cline { 2 - 3 } & Average & Maximal \\
\hline $220^{\mathrm{a}}$ & $0.22 \pm 0.14$ & 0.72 \\
$330^{\mathrm{a}}$ & $0.32 \pm 0.07$ & 0.36 \\
$650^{\mathrm{b}}$ & $0.20 \pm 0.07$ & 0.48 \\
$1400^{\mathrm{b}}$ & $0.13 \pm 0.05$ & 0.25 \\
\hline
\end{tabular}

${ }^{\mathrm{a}} \mathrm{PhBR} 4$

${ }^{\mathrm{b}} \mathrm{PhBR} 3$

filamentous cyanobacteria [29, 30]. Besides, this effect may also depend on other factors: the cell concentration, duration of illumination and range of the light intensities. Data of Experiment \#2 (Table 1) differ from those of Experiment \#1 (Fig. 5a), where no light inhibition was observed. We can ascribe it to lower-light intensities, higher Chl concentration $\left(\sim 20 \mathrm{mg} \mathrm{Chl} \mathrm{L}^{-1}\right)$ as well as lower $\mathrm{O}_{2}$ concentration (due to Ar gas phase) in Experiment \#1. Our data (Fig. 5a) referred to prolonged $\mathrm{H}_{2}$ production. When cell suspension of the same culture in short-term ( $2 \mathrm{~min}$ ) experiments was tested, we observed no inhibition even at $2800 \mu \mathrm{mol}$ photon $\mathrm{m}^{-2} \mathrm{~s}^{-1}$ [25]. In shortterm experiments, the $\mathrm{Hup}^{-}$mutant of $A$. variabilis PK84 demonstrated only a slight sensitivity to $\mathrm{O}_{2}$ concentration [31]. In our Experiment \#2 at various light intensities, there were no essential differences in $\mathrm{O}_{2}$ concentrations measured against the background of air flow (not shown). However, since the air flow was delivered above the surface, the intimate conditions in culture may be different and $\mathrm{pO}_{2}$ may be elevated. Generally speaking, the light delivery to the culture was inhomogeneous due to absence of continuous mixing [28]. In a well-mixed outdoor culture A. variabilis $\mathrm{PK} 84$, the $\mathrm{H}_{2}$ rate did not decrease but conversion efficiency of light $/ \mathrm{H}_{2}$ energy decreased at high daily irradiance [16].

\section{Summary of two experiments}

Experiments \#1 and \#2 were carried out with different initial Chl concentrations (Table 2). However, an increase in $\mathrm{Chl}$ concentration in the course of the experiment was not observed, there was even a slight decrease. This could be explained by a decrease in the specific content of $\mathrm{Chl}$ due to high natural light intensity, which was noted earlier [32]. Indeed, OD (another growth indicator), in contrast to Chl concentration, increased by approximately $50 \%$ during Experiment \#2 (PhBRs 3, 4). This can be due to accumulation of saccharides. On the other hand, an increase in OD with a decrease in Chl content may also indicate bacteriological contamination of the culture. Such a change in parameters in Experiment \#2 (PhBR 4) was actually accompanied by contamination, which was confirmed by microscopy after $110 \mathrm{~h}$ (not shown). At the same time, $\mathrm{pO}_{2}$ also decreased, and the $\mathrm{H}_{2}$ production ceased, which were subsequently not restored (therefore, the experiment has been stopped).

The average rate of $\mathrm{H}_{2}$ production did not exceed 7.2-7.4 $\mathrm{mL} \mathrm{L}^{-1} \mathrm{day}^{-1}$ during 5 days, whereas the maximal volumetric $\mathrm{H}_{2}$ production rate amounted to 18.5-20.6 mL L ${ }^{-1}$ day $^{-1}$ (Table 2), but it took place only for a few hours $(2-4 \mathrm{~h})$. The maximal rate per $1 \mathrm{mg} \mathrm{Chl}$ amounted to $3.8 \mathrm{~mL} \mathrm{day}^{-1}$ in Experiment \#2 with lower Chl content. Hydrogen accumulation reached $33.2 \mathrm{~mL} \mathrm{~L}^{-1}$. Compared to the best outdoor experiments [14, 16], the rather short duration and quite low values of $\mathrm{H}_{2}$ production in our study can be due to several reasons: the simple PhBR design, poor mixing and culture heterogeneity, and uncontrolled pH. Natural conditions were not optimal as well. Contamination was still a problem even if cyanobacteria were cultivated with antibiotics. As a disadvantage, we should mention poor reliability of plastic bags when using without mechanical protection. Actually, some bags were rejected after the start of experiments due to damage.

We would like to emphasize that during almost 2 decades, there were only a few attempts of outdoor $\mathrm{H}_{2}$ production using filamentous or unicellular cyanobacteria [14, $16,17]$. Despite the successful laboratory experiments and
Table 2 Main characteristics of two outdoor experiments

\begin{tabular}{|c|c|c|c|c|c|c|c|c|c|}
\hline \multirow[t]{4}{*}{ Exp } & \multirow[t]{4}{*}{ PhBR } & \multirow{4}{*}{$\begin{array}{l}\text { Chl, mg L } \\
-1 \\
\text { Init/fin }\end{array}$} & \multicolumn{4}{|c|}{$\mathrm{H}_{2}$ production } & \multirow{2}{*}{\multicolumn{3}{|c|}{$\begin{array}{l}\text { Maximal content in } \\
\text { the gas phase, } \%\end{array}$}} \\
\hline & & & \multirow{2}{*}{\multicolumn{2}{|c|}{$\frac{\text { Rate }}{\mathrm{mL} \mathrm{L}^{-1} \mathrm{day}^{-1}}$}} & \multicolumn{2}{|l|}{ Volume } & & & \\
\hline & & & & & \multirow{2}{*}{ 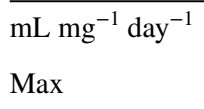 } & \multirow{2}{*}{$\begin{array}{l}\mathrm{mL} \mathrm{L}^{-1} \\
\operatorname{Max}\end{array}$} & \multirow[b]{2}{*}{$\mathrm{H}_{2}$} & \multirow[b]{2}{*}{$\mathrm{O}_{2}$} & \multirow[b]{2}{*}{$\mathrm{N}_{2}$} \\
\hline & & & Aver & Max & & & & & \\
\hline$\# 1$ & 1 & $23.3 / 18.4$ & 7.4 & 18.5 & 0.8 & 33.2 & 1.1 & 9.8 & 4.0 \\
\hline$\# 1$ & 2 & $23.3 / 18.0$ & 7.2 & 20.6 & 0.9 & 31.8 & 1.1 & 9.7 & 0.7 \\
\hline$\# 2$ & $3^{\mathrm{a}}$ & $4.1 / 3.4$ & 2.3 & 11.5 & 2.8 & 10.5 & 0.03 & 18.4 & 77 \\
\hline$\# 2$ & $4^{\mathrm{a}}$ & $4.5 / 4.2$ & 3.4 & 17.3 & 3.8 & 12.8 & 0.03 & 17.9 & 75 \\
\hline
\end{tabular}

${ }^{\mathrm{a}}$ Light intensities during Experiment \#2 were variable (see footnote to Table 1) 
theoretical considerations, actual outdoor $\mathrm{H}_{2}$ production is still a challenge. It seems that practical devices need to be more complicated and cost consuming to provide reliable hydrogen. Besides, weather conditions (geographic region) should be chosen carefully. In general, our very first attempt in outdoor cultivation proves that photoautotrophic $\mathrm{H}_{2}$ production by cyanobacteria in Moscow region is feasible, however, there is still great room for improvement.

\section{Conclusions}

Our experiments prove for the first time that $\mathrm{H}_{2}$ production by cyanobacteria in cheap plastic bags is feasible outdoors in Moscow region in the middle-late summer. However, the rates and yields were lower than in best experiments described earlier. We suggest that rather low $\mathrm{H}_{2}$ production in our outdoor experiments can be attributed to several reasons: suboptimal weather conditions (low night temperatures, high daytime illumination), unsuitable culture conditions (heterogeneity due to inappropriate mixing) and contamination.

Acknowledgements Authors thank Prof. Inoue, K. for presenting to us the used strain of cyanobacterium. Experimental data acquisition was supported by the Russian Foundation of Basic Research No 15-54-50032, whereas data analysis and the paper preparation were supported by Russian Ministry of Science and Education (AAAA-A17-117030110141-2).

\section{Compliance with ethical standards}

Conflict of interest The authors declare that they have no conflict of interest.

Open Access This article is distributed under the terms of the Creative Commons Attribution 4.0 International License (http://creativeco mmons.org/licenses/by/4.0/), which permits unrestricted use, distribution, and reproduction in any medium, provided you give appropriate credit to the original author(s) and the source, provide a link to the Creative Commons license, and indicate if changes were made.

\section{References}

1. Sakurai, H., Masukawa, H., Kitashima, M., Inoue, K.: A feasibility study of large-scale photobiological hydrogen production utilizing mariculture-raised cyanobacteria. Adv. Exp. Med. Biol. 675, 291-303 (2010)

2. Sakurai, H., Masukawa, H., Kitashima, M., Inoue, K.: Photobiological hydrogen production: bioenergetics and challenges for its practical application. J. Photochem. Photobiol. C Photochem. Rev. 17, 1-25 (2013)

3. Tsygankov, A.A., Khusnutdinova, A.N.: Hydrogen in metabolism of purple bacteria and prospects of practical application. Microbiology 84(1), 1-22 (2015)
4. Hallenbeck, P.C., Liu, Y.: Recent advances in hydrogen production by photosynthetic bacteria. Int. J. Hydrogen Energy 41(7), 4446-4454 (2016)

5. Sakurai, H., Tsygankov, A.A.: Chapter 16. Photobiological biohydrogen production. In: Basile, A., Dalena, F. (eds.) Second and Third Generation of Feedstocks. Elsevier, New York (2019)

6. Deprá, M.C., Mérida, L.G.R., de Menezes, C.R., Zepka, L.O., Jacob-Lopes, E.: A new hybrid photobioreactor design for microalgae culture. Chem. Eng. Res. Des. 144, 1-10 (2019)

7. Tredici, M.: Mass production of microalgae: photobioreactors. In: Richmond, A. (ed.) Handbook of Microalgal Culture: Biotechnology and Applied Phycology, pp. 178-214. Blackwell Publishing, Oxford (2004)

8. Ugwu, C.U., Aoyagi, H., Uchiyama, H.: Photobioreactors for mass cultivation of algae. Bioresour. Technol. 99, 4021-4028 (2008)

9. Sakurai, H., Masukawa, H., Kitashima, M., Inoue, K.: How Close we are to achieving commercially viable large-scale photobiological hydrogen production by cyanobacteria: a review of the biological aspects. Life 5(1), 997-1018 (2015)

10. Dutta, D., De, D., Chaudhuri, S., Bhattacharya, S.: Hydrogen production by cyanobacteria. Microb. Cell Fact. 4(1), 1-11 (2005)

11. Happe, T., Schutz, K., Bohme, H.: Transcriptional and mutational analysis of the uptake hydrogenase of the filamentous cyanobacterium Anabaena variabilis ATCC 29413. J. Bacteriol. 182(6), 1624-1631 (2000)

12. Yoshino, F., Ikeda, H., Masukawa, H., Sakurai, H.: High photobiological hydrogen production activity of a Nostoc sp. PCC 7422 uptake hydrogenase-deficient mutant with high nitrogenase activity. Mar. Biotechnol. 9(1), 101-112 (2007)

13. Fernández-Sevilla, J.M., Acién-Fernández, F.G., Molina-Grima, E.: Photobioreactors design for hydrogen production. In: Zannoni, D., De Philippis, R. (eds.) Microbial Bioenergy: Hydrogen Production, pp. 291-320. Springer Science + Business Media, Dordrecht (2014)

14. Lindblad, P., Christensson, K., Lindberg, P., Fedorov, A., Pinto, F., Tsygantov, A.A.: Photoproduction of $\mathrm{H}_{2}$ by wildtype Anabaena PCC 7120 and a hydrogen uptake deficient mutant: from laboratory experiments to outdoor culture. Int. J. Hydrogen Energy 27(11-12), 1271-1281 (2002)

15. Borodin, V.B., Tsygankov, A.A., Rao, K.K., Hall, D.O.: Hydrogen production by Anabaena variabilis PK84 under simulated outdoor conditions. Biotechnol. Bioeng. 69(5), 478-485 (2000)

16. Tsygankov, A.A., Fedorov, A.S., Kosourov, S.N., Rao, K.K.: Hydrogen production by cyanobacteria in an automated outdoor photobioreactor under aerobic conditions. Biotechnol. Bioeng. 80(7), 777-783 (2002)

17. Touloupakis, E., Benavides, A.M.S., Cicchi, B., Torzillo, G.: Growth and hydrogen production of outdoor cultures of Synechocystis PCC 6803. Algal Res. 18, 78-85 (2016)

18. Amos, W.A.: Updated cost analysis of photobiological hydrogen production from Chlamydomonas reinhardtii green algae-milestone completion report. NREL/MP-560-35593 (2004). http:// www.nrel.gov.docs.fy04osti/35593.pdf. Accessed 27 Jan 2011

19. Sakurai, H., Masukawa, H.: Promoting R \& D in photobiological hydrogen production utilizing mariculture-raised cyanobacteria. Mar. Biotechnol. 9(2), 128-145 (2007)

20. Kitashima, M., Masukawa, H., Sakurai, H., Inoue, K.: Flexible plastic bioreactors for photobiological hydrogen production by hydrogenase-deficient cyanobacteria. Biosci. Biotechnol. Biochem. 76(4), 831-833 (2012)

21. Masukawa, H., Mochimaru, M., Sakurai, H.: Hydrogenases and photobiological hydrogen production utilizing nitrogenase system in cyanobacteria. Int. J. Hydrogen Energy 27(11-12), 1471-1474 (2002) 
22. Allen, M.B., Arnon, D.I.: Studies on nitrogen-fixing blue-green algae. I. Growth and nitrogen fixation by Anabaena cylindrica Lemm. Plant. Physiol. 30(4), 366-372 (1955)

23. Laurinavichene, T., Tekucheva, D., Laurinavichius, K., Ghirardi, M., Seibert, M., Tsygankov, A.: Towards the integration of dark and photo fermentative waste treatment. 1. Hydrogen photoproduction by purple bacterium Rhodobacter capsulatus using potential products of starch fermentation. Int. J. Hydrogen Energy 33(23), 7020-7026 (2008)

24. Jensen, B.B., Cox, R.P.: Direct measurements of steady-state kinetics of cyanobacterial $\mathrm{N}_{2}$ uptake by membrane-leak mass spectrometry and comparisons between nitrogen fixation and acetylene reduction. Appl. Environ. Microbiol. 45(4), 1331-1337 (1983)

25. Romanova, A.I., Laurinavichene, T.V., Tsygankov, A.A.: Features of Anabaena PCC $7120 \Delta$ Hup mutants with amino acid substitutes in nitrogenase. Plant Physiol. (2020) (in press)

26. Torzillo, G., Vonshak, A.: Effect of light and temperature on the photosynthetic activity of the cyanobacterium Spirulina platensis. Biomass Bioenergy 6(5), 399-403 (1994)

27. Masukawa, H., Sakurai, H., Hausinger, R.P., Inoue, K.: Sustained photobiological hydrogen production in the presence of $\mathrm{N}_{2}$ by nitrogenase mutants of the heterocyst-forming cyanobacterium Anabaena. Int. J. Hydrogen Energy 39(34), 19444-19451 (2014)

28. Richmond, A.: Mass culture of cyanobacteria. In: Mann, N.H., Carr, N.G. (eds.) Photosynthetic Prokaryotes, pp. 181-208. Plenum Press, New York (1992)
29. Vargas, S.R., dos Santos, P.V., Zaiat, M., Calijuri, M.C.: Optimization of biomass and hydrogen production by Anabaena sp. (UTEX1448) in nitrogen-deprived cultures. Biomass Bioenergy 111, 70-76 (2018)

30. Yodsang, P., Raksajit, W., Aro, E.-M., Mäenpää, P., Incharoensakdi, A.: Factors affecting photobiological hydrogen production in five filamentous cyanobacteria from Thailand. Photosynthetica 56(1), 334-341 (2018)

31. Tsygankov, A., Serebryakova, L., Rao, K., Hall, D.: Acetylene reduction and hydrogen photoproduction by wild type and mutant strains of Anabaena at different $\mathrm{CO}_{2}$ and $\mathrm{O}_{2}$ concentrations. FEMS Microbiol. Lett. 167(1), 13-17 (1998)

32. Marques, A.E., Barbosa, A.T., Jotta, J., Coelho, M.C., Tamagnini, P., Gouveia, L.: Biohydrogen production by Anabaena sp. PCC 7120 wild-type and mutants under different conditions: light, nickel, propane, carbon dioxide and nitrogen. Biomass Bioenergy 35(10), 4426-4434 (2011)

Publisher's Note Springer Nature remains neutral with regard to jurisdictional claims in published maps and institutional affiliations. 